\title{
Correção da geometria do ventrículo esquerdo com prótese semi-rígida de pericárdio bovino
}

Domingo M. BRAILE*, Ricardo M. MUSTAFÁ*, José Luiz Verde dos SANTOS*, Roberto V. ARDITO*, Marcos ZAIANTCHICK*, Wilson Miguel C. COELHO*, Sérgio Aloísio C. GARZON*

BRAILE, D. M.; MUSTAFÁ, R. M.; SANTOS, J. L. V.; ARDITO, R. V.; ZAIANTCHICK, M.; COELHO, W. M.; GARZON, S. A. - Correção da geometria do ventrículo esquerdo com prótese semi-rígida de pericárdio bovino. Rev. Bras. Cir. Cardiovasc., 6(2): 109-115, 1991.

RESUMO: Os aneurismas ventriculares são graves complicaçōes dos infartos miocárdicos, levando a diminuição da função ventricụlar e elevação da morbi-mortalidade. A correção cirúrgica proposta por COOLEY, em 1958, mudou a evolução desta complicação. JATENE, em 1985, contribuiu mundialmente com a Reconstruçăo Geométrica do Ventrículo Esquerdo, mostrando resultados funcionais superiores $\boldsymbol{e}$ baixa mortalidade. Modificando a técnica de reconstrução geomética, utilizamos uma prótese semi-rigida de pericárdio bovino duplo com anel de implantaçāo de Dacron, do qual se projeta uma aba, também de pericárdio bovino. Apresentada com diâmetros de 19 a $27 \mathrm{~mm}$, conta com um aro radiopaco para identificaçăo radiológica. Abrindo-se o aneurisma, a área de transição entre o tecido contrátil e a zona fibrótica é delimitada. São passados pontos separados em $U$ invertido de poliéster 2-0 com almofadas de Teflon em toda a circunferência de transição. Com medidor próprio, avalia-se o colo original a partir do qual o aneurisma se dilatou, estabelecendo-se o diâmetro adequado da prótese. Então os pontos são passados no anel de Dacron, reduzindo o colo do aneurisma ao diâmetro do anel, dando ao ventrículo a sua forma original, sem perda de tecido nobre. A sutura contínua da aba de pericárdio bovino, que se projeta do anel, com o tecido fibroso restante complementa a hemostasia. De 16 pacientes submetidos a técnica, 11 foram estudados através da "Definição das 100 Cordas de Encurtamento". A média da fração de ejeção (Dodge/Kennedy $n=0,55$ a 0,81) pré-operatória foi de 0,37 e de 0,53 no pós-operatório, aumentando em $43 \%$ a função ventricular, com boa evolução clínica pós-operatória.

DESCRITORES: ventrículo esquerdo, cirurgia, reconstrução geométrica; próteses valvulares cardíacas, pericárdio bovino.

\section{INTRODUÇÃO}

Os aneurismas ventriculares são graves complicaçōes do infarto do miocárdio, com importante repercussão clínica (insuficiência cardíaca, tromboembolismo, angina pectoris e arritmias), sendo responsável por grande parte da mortalidade dos pacientes infartados.
A reconstrução cirúrgica tem sido realizada com diferentes técnicas, desde que COOLEY et alii ${ }^{4}$, em 1958, descreveram o primeiro caso de ressecção e sutura de aneurisma ventricular.

Os resultados satisfatórios de JATENE ${ }^{7}$, em 1985, com a reconstrução geométrica, ampliaram as indica-

Trabalho realizado no Instituto de Moléstias Cardiovasculares de Săo José do Rio Preto. Săo Paulo, SP, Brasil.

Apresentado ao 18: Congresso Nacional de Cirurgia Cardiaca. Rio de Janeiro, RJ, 5 e 6 de abril, 1991.

- Do Instituto de Moléstias Cardiovasculares de São José do Rio Preto.

Endereço para separatas: Domingo M. Braile. Rua Castelo D'Água, 3030.15015 São José do Rio Preto, SP, Brasil. 
BRAILE, D. M.; MUSTAFÁ, R. M.; SANTOS, J. L. V.; ARDITO, R. V.; ZAIANTCHICK, M.; COELHO, W. M.; GARZON, S. A. Correção da geometria do ventrículo esquerdo com prótese semi-rígida de pericárdio bovino. Rev. Bras. Cir. Cardiovasc., 6(2): 109-115, 1991.

çōes e melhoraram o prognóstico para os aneurismas de colo largo.

A utilização de prótese semi-rígida de pericárdio bovino IMC é por nós apresentada em 11 casos de aneurisma ventricular ântero-apical de colo largo submetidos a reconstrução geométrica.

\section{CASUÍSTICA E MÉTODOS}

Apresentamos uma nova prótese para reconstrução da geometria do ventrículo esquerdo (VE), confeccionada com pericário bovino e preservada em glutaraldeído. Sua montagem é feita sobre anel de Delrin \$, que apresenta um aro de aço inoxidável, sendo revestido de Dacron. A prótese é disponível nos diâmetros de 19 a $27 \mathrm{~mm}$, acompanhado-a os medidores correspondentes.

Dos 16 procedimentos, 11 foram comparados entre si, no pré e no pós-opertório. Avaliamos a fração de ejeção pelo método de Dodge/Kennedy e a contratilidade segmentar pela "Definição das 100 Cordas de Encurtamento".

\section{Técnica Cinúrgica}

A cirurgia é realizada sob normotermia com cardioplegia sangüínea contínua normotérmica anterógrada e/ ou retrógrada. Se houver indicação de revascularizaçāo do miocárdio, inclusive da artéria responsável pelo aneurisma (quando pérvia), esta é feita antes da abordagem ventricular.

Procede-se à ventriculotomia com extensão suficiente para permitir a exposiçăo do colo do aneurisma e a inclusão da prótese. Observando-se a área de perfusão e a transiçẩo fibromuscular, o colo, a partir do qual a parede ventricular se dilatou, é delimitado. A avaliação cuidadosa do colo é fundamental para preservaçāo da função ventricular e do volume da cavidade.

Com fio de poliéster 2.0 ancorado em almofadas de Teflon ou de pericárdio bovino, são passados pontos separados em $U$ ao longo da borda ventrículo-aneurismática (Figura 1). Com o uso de medidor próprio, o diâmetro da prótese é escolhido cuidadosamente, observando-se o volume cavitário residual (Figura 2). Em seguida os pontos são passados na prótese (Figura 3) que então é posicionada e fixada no colo, constituindo a neoparede ventricular (Figura 4). A aba de pericádio bovino é, então, suturada em sutura contínua com fio de poliéster 2.0 para fortalecer a fixação e propiciar hemostasia.

A porçāo aneurismática do VE não é ressecada e sim suturada sobre a prótese (Figura 5).

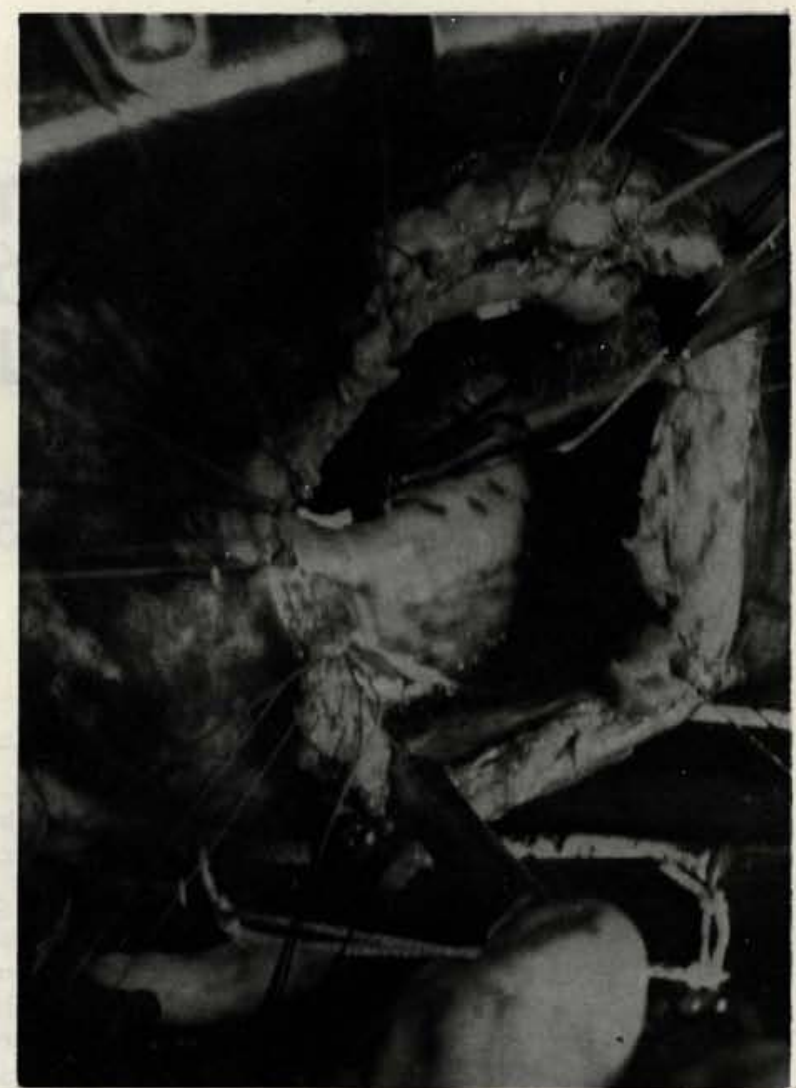

Fig. 1-A

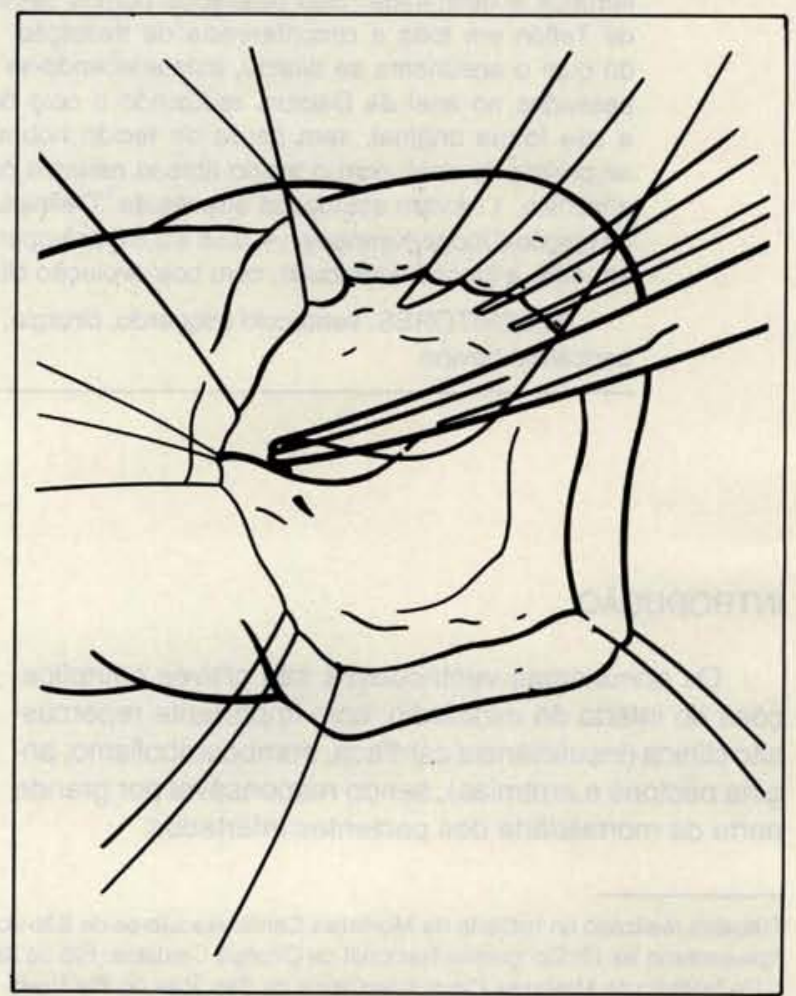

Fig. 1-B 
BRAILE, D. M.; MUSTAFÁ, R. M.; SANTOS, J. L. V.; ARDITO, R. V.; ZAIANTCHICK, M.; COELHO, W. M.; GARZON, S. A. Correção da geometria do ventrículo esquerdo com prótese semi-rígida de pericárdio bovino. Rev. Bras. Cir. Cardiovasc., 6(2): 109-115, 1991.

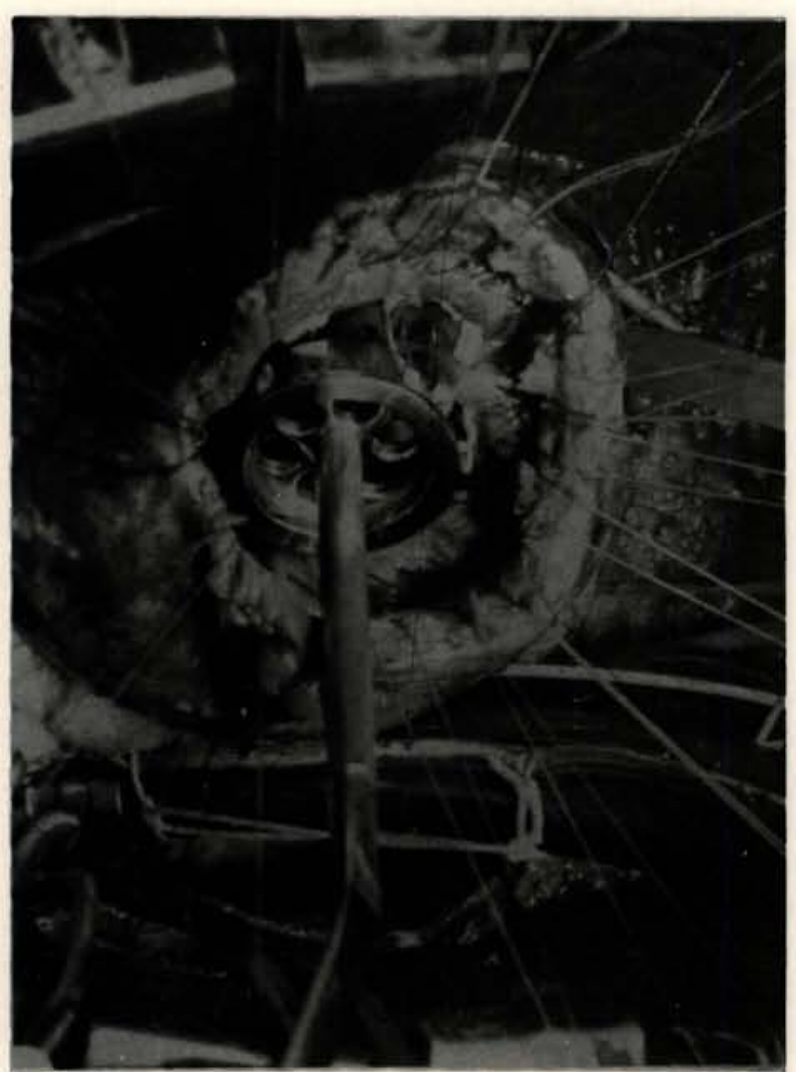

Fig. 2-A

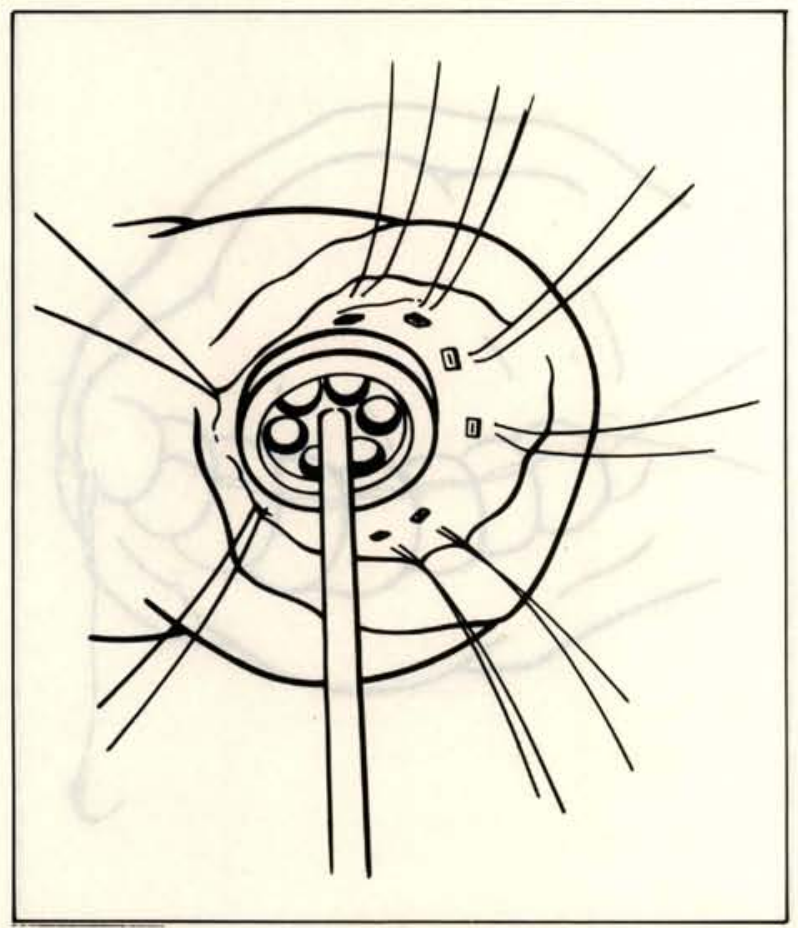

Fig. 2-B

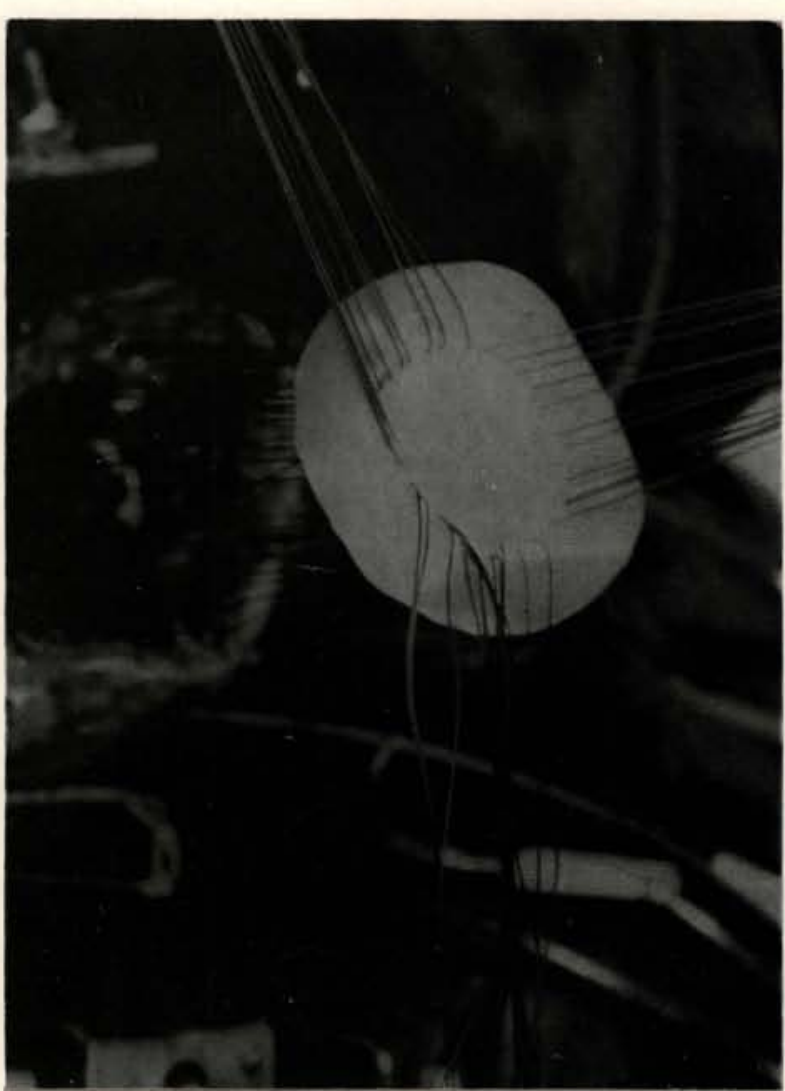

Fig. 3-A

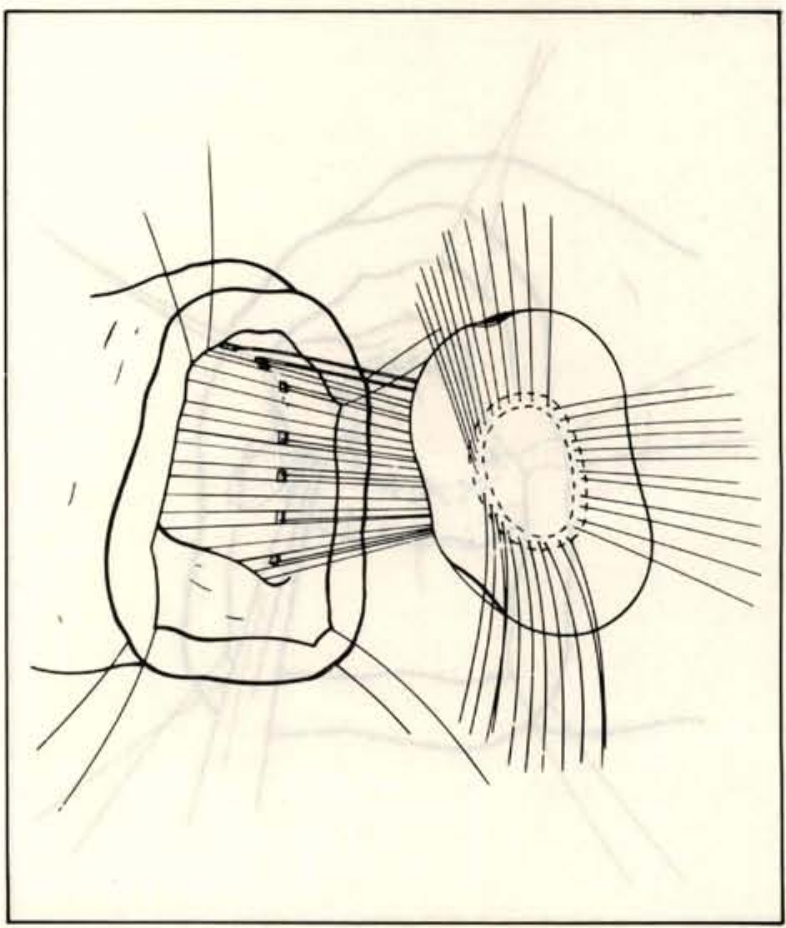

Fig. 3-B 
BRAILE, D. M.; MUSTAFÁ, R. M.; SANTOS, J. L. V.; ARDITO, R. V.; ZAIANTCHICK, M.; COELHO, W. M.; GARZON, S. A. Correção da geometria do ventrículo esquerdo com prótese semi-rígida de pericárdio bovino. Rev. Bras. Cir. Cardiovasc., 6(2): 109-115, 1991.

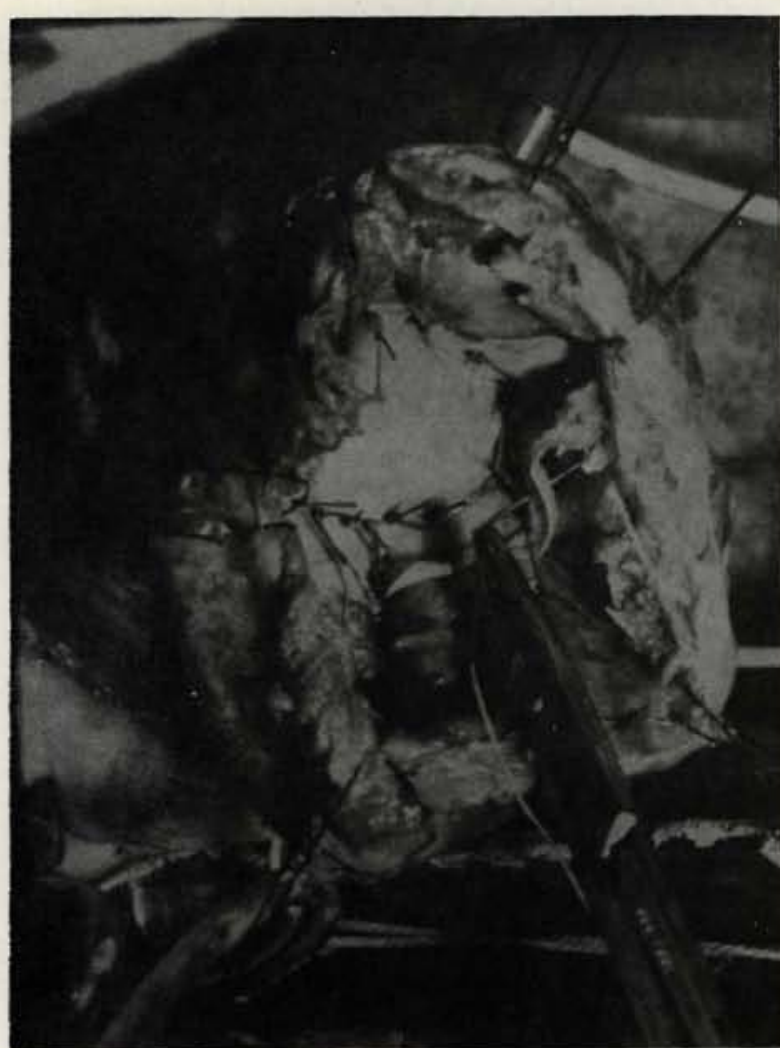

Fig. 4-A

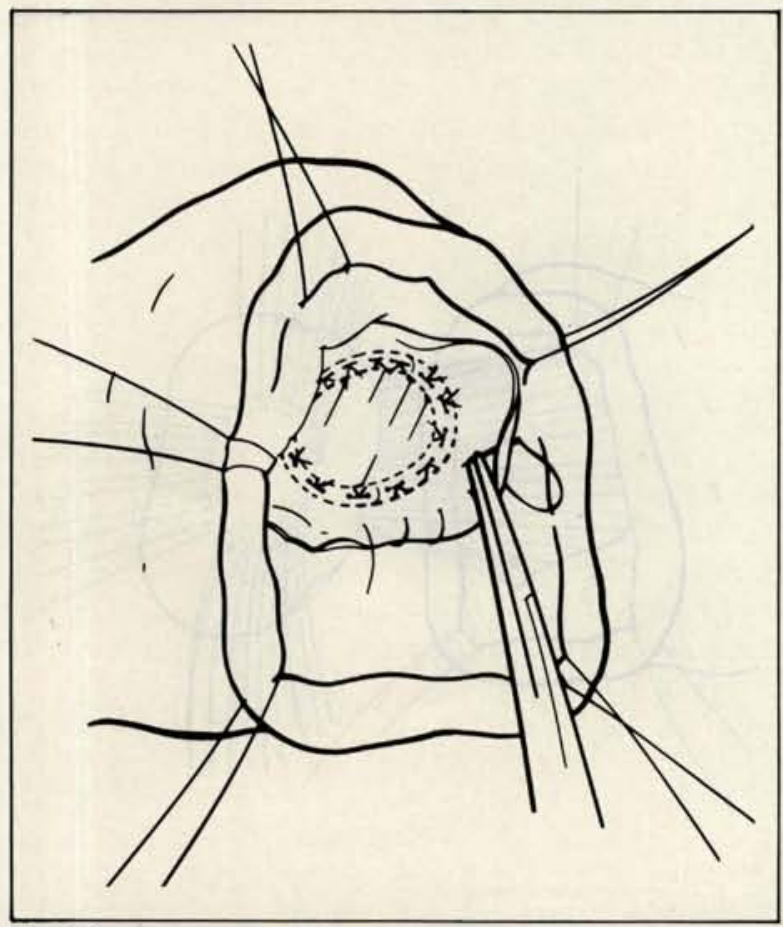

Fig. 4-B

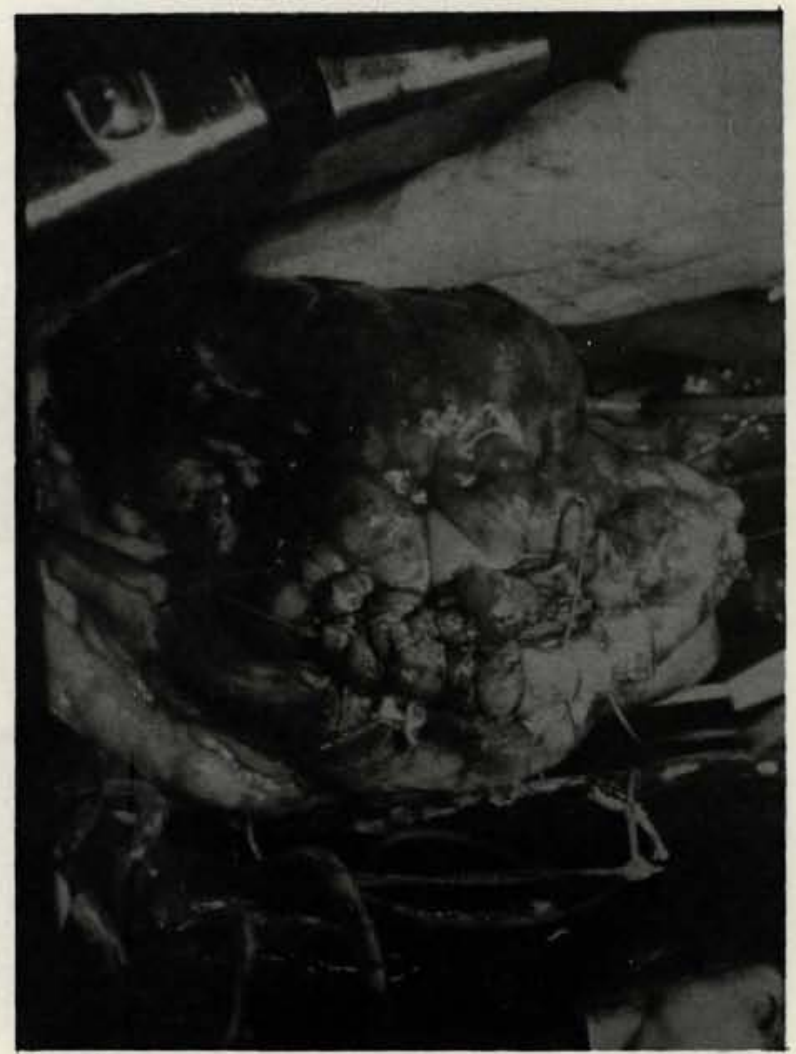

Fig. 5-A

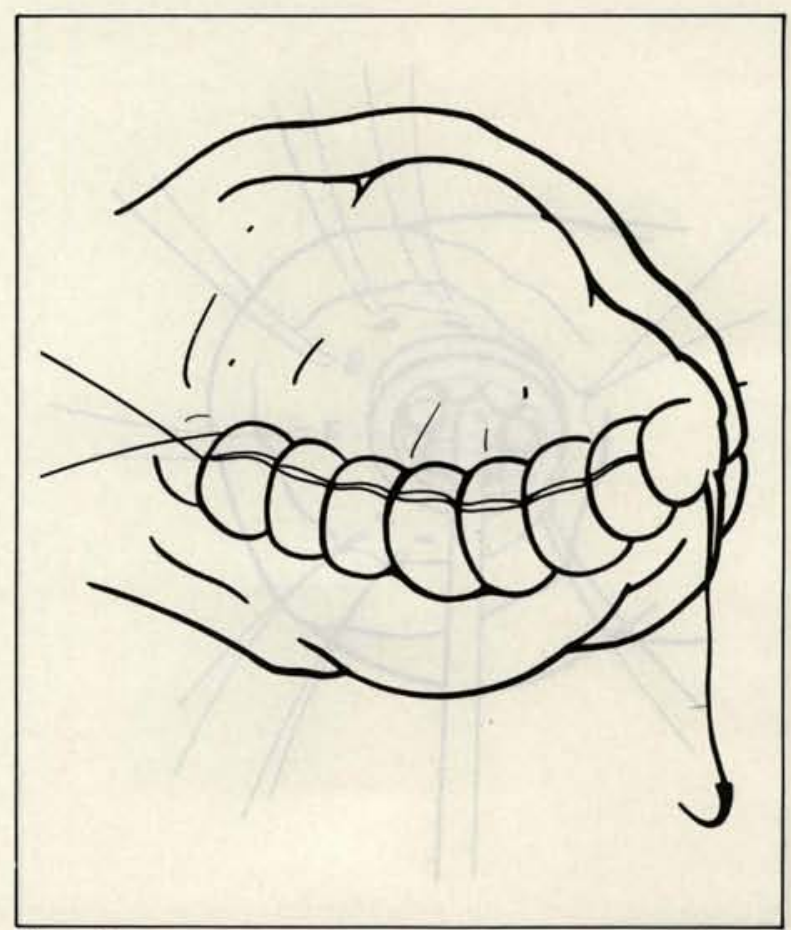

Fig. 5-B 
BRAILE, D. M.; MUSTAFÁ, R. M.; SANTOS, J. L. V.; ABDITO, R. V.; ZAIANTCHICK, M.; COELHO, W. M.; GARZON, S. A. Correção da geometria do ventrículo esquerdo com prótese semi-rígida de pericárdio bovino. Rev. Bras. Cir. Cardiovasc., 6(2): 109-115, 1991.

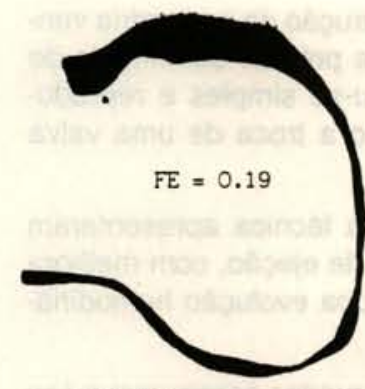

S.S, $52 A$

Fig. 6

GRÁFICO 1

COMPARAÇÃO ENTRE DOIS VENTRICULOS.

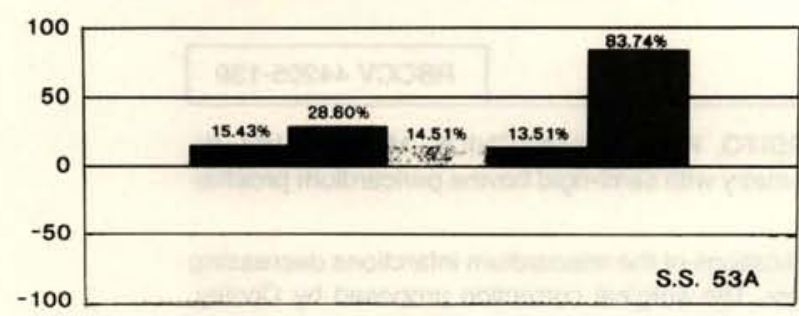

REgiao anterior 1

* REgIAO APICAL

REgIAO INFERIOR 2

\section{RESULTADOS}

A avaliação pré-operatória da fração de ejeção mostrou média de 0,37 aumentando para 0,53 no pós-operatório (Figura 6), com melhora da contratilidade segmentar (Gráfico 1). Os pacientes apresentaram boa evolução pós-operatória, sem ocorrência significante de intercorrências.

\section{DISCUSSÃO}

Sendo os aneurismas ventriculares complicaçōes comuns do infarto miocárdico, com repercussão clínica importante, muitas maneiras foram propostas ${ }^{2}$ para sua correção cirúrgica (plicação, excisão e sutura, imbricação e interposição de patch ).

Os aneurismas de colo largo continuavam com solução cirúrgica difícil, quando JATENE ${ }^{7}$, em 1985, apresentou a técnica de reconstrução geométrica do VE, eliminando fatores desfavoráveis à correção, como a não redução importante do volume ventricular, a supressão da área discinética septal e manutenção da conformação elíptica ventricular.

A eficácia deste tipo de reconstrução incentivou modelos semelhantes, usando próteses rígidas ou semi-ri- gidas para restaurar a geometia, principalmente quando o aneurisma ventricular se constituía na indicação cirúrgica.

BRANCO et alii ${ }^{1}$, em 1982, descreveram uma prótese de Teflon e Dacron com abas largas que apresentava forma semelhante à que foi por nós desenvolvida. Talvez a rigidez da mesma e o uso de grandes diâmetros, com o conceito de simplesmente fechar o aneurisma sem reduzir-lhe o colo, tenham sido a causa da descontinuidade do seu uso.

A prótese por nós apresentada, constituída de material biológico (pericárdio bovino IMC) preservado em glutaraldeído, tem propriedades físicas (tensão, elasticidade e resistência) indispensáveis para sua utilização. Por ser montada sobre anel semi-rígido, permite a manutenção do volume ventricular diastólico e a ausência de distorção na sístole. A presença de um anel de aço na base do anel de Delrin (® permite sua avaliação pós-operatória não invasiva por meio de radiografia simples de tórax. A prótese que empregamos é atrombogênica, e mesmo assim a agregabilidade plaquetária é atenuada ainda mais pelo uso rotineiro de ácido acetil salicilico $100 \mathrm{mg} /$ dia por via oral.

Recentemente COOLEY ${ }^{2,3}$ apresentou a técnica de endoaneurismorrafia e concomitância a esta por nós desenvolvida. Algumas diferenças são, contudo, nítidas entre os dois procedimentos: 1) a delimitação do colo do aneurisma realiza-se com pontos separados de poliéster em $U$ com almofadas de Teflon ou pericárdio; 2) a avaliação da redução a ser realizada no colo para devolver a geometria do ventrículo é feita de forma padronizada, com uso de medidores, o que permite uma previsão do resultado a ser obtido e pode ser repetida com facilidade por qualquer cirurgião; 3 ) o pericárdio bovino duplo que reveste $o$ anel é absolutamente impermeável ao sangue; 4 ) a sutura entre a aba de pericárdio bovino e o tecido fibrótico do aneurisma permite completar a hemostasia; 5) a sutura em jaquetão dos tecidos aneurismáticos sobre a prótese permite recobrí-la sem que a geometria do ventrículo se altere; 6 ) o tecido biológico empregado é atrombogênico.

Optamos por realizar, primeiramente, as possíveis revascularizaçōes do miocárdio pela facilidade técnica e melhor proteção miocádica com cardioplegia contínua. A artéria responsável pelo aneurisma tem sido freqüentemente revascularizada, uma vez que, por esta técnica, não ressecamos o tecido aneurismático, permitindo a manutenção da artéria nutridora da área. A proteção miocárdica contínua durante esse procedimento mantém protegido o miocárdio e permite a visibilização das áreas perfundidas (miocárdio viável) ou isquêmicas (fibrose), auxiliando a delimitação da zona de transição ventrículoaneurismática. Ao contrário, $\mathrm{JATENE}^{7}$ preconiza que o colo deve ser definido através da observação da contratilidade ventricular com o coração batendo. 
BRAILE, D. M.; MUSTAFÁ, R. M.; SANTOS, J. L. V.; ARDITO, R. V.; ZAIANTCHICK, M.; COELHO, W. M.; GARZON, S. A. Correção da geometria do ventrículo esquerdo com prótese semi-rígida de pericárdio bovino. Rev. Bras. Cir. Cardiovasc., 6(2): 109-115, 1991.

A possibilidade de excluir a porçāo septal aneurismática (Figura 1) melhora e eficácia contrátil, remodela o ventrículo e evita a formação de trombo.

Os resultados obtidos com a reconstrução geométrica têm sido considerados semelhantes às técnicas mais simples, como a plicatura ${ }^{8}$. É importante porém observar que a indicaçāo cirúrgica tem reservado à técnica de reconstrução geométrica aos aneurismas mais graves e com colo largo ${ }^{5,6}$ que, de outra forma, levariam à elevação da mortalidade operatória e a resultados cirúrgicos insatisfatórios.
Assim, a técnica de reconstrução da geometria ventricular esquerda, com o uso de prótese semi-rígida de pericárdio bovino IMC, mostrou-se simples e reprodutível, por ser padronizada como a troca de uma valva cardíaca.

Os pacientes submetidos á técnica apresentaram aumento significante na fração de ejeção, com melhora na contratilidade segmentar e boa evolução hemodinâmica e clínica.

Os resultados por nós observados asseguram o seu emprego como rotina para a cirurgia de aneurisma grave de colo largo.

RBCCV 44205-139

BRAILE, D. M.; MUSTAFÁ, R. M.; SANTOS, J. L. V.; ARDITO, R. V.; ZAIANTCHICK, M.; COELHO, W. M.; GARZON, S. A. - Correcton of the left ventricle geometry with semi-rigid bovine pericardium prosthesis. Rev. Bras. Cir. Cardiovasc., 6(2): 109-115, 1991

ABSTRACT: The ventricle aneurysms are severe complications of the miocardium infarctions decreasing the ventricle function and increasing the morbi-mortality rate. The surgical correction proposed by Cooley, in 1958, has changed the evolution of this complication. In 1985, Jatene gave a worldwide contribution to the Geometrical Reconstruction of the left ventricle, showing superior functional results and low mortality rate. We present a technique modification of the aneurysmectomy with geometrical reconstruction utilizing semi-rigid prosthesis double-coated with bovine pericardium with an implantation stent made of Dacron out of which the flap is projected, also made of bovine pericardium. They are available with their 19 up to $27 \mathrm{~mm}$ wide diameter with the corresponding sizer and they have a radiopaque stent for radiological identification. Once the aneurysm has been opened, the transition are between contractile tissue and the fibrous zone is delimited. Polyester $2-0$ stitches are passed separately in inverted $U$ shape supported by "pledgets" of Teflon all around the venticle circle and with the diameter sizer we evaluate the aneurysm original transaction which enlarged with the time, setting the right size of the prosthesis. The Dacron stent is then shown reducing the aneurysm transition to the size of the ring so that it gives the ventricle its original shape with no loss of noble tissue, remodellign its cavity. Then with a continuous suture from the bovine pericardium flap, projected from the stent and the fibrous tissue, the hemostasia is completed. From 16 patients submitted to the technique, 11 patients studied by the 100 -shortening-chordae computorized system. The average ejection fraction (Dodge/Kennedy $N=0.55-0.81$ ) of the pre-operative was 0.37 and 0.53 for the post-operative showing a $43 \%$ improvement in the miocardium function.

DESCRIPTORS: left ventricle, surgery, geometrical reconstruction; heart valves prosthesis, bovine pericardium.

\section{REFERÊNCIAS BIBLIOGRÁFICAS}

1 BRANCO, J. N. R.; BUFFOLO, E.; ANDRADE, J. C. S.; SUCCI, J. E.; LEĀO, L. E. V.; BISCEGLI, J. F.; RIBEIRO, E.; CARVALHO, A. C. C.; GODOY, M. F.; GALLUCCI, C. - Aneurismectomia de ventriculo esquerdo: reconstrução geométrica com utilização de prótese semi-rígida de Teflon. Arq. Bras. Cardiol., 39: 241-245, 1982.

2 COOLEY, D. A. - Ventricular endoaneurysmormaphy: results of an improved method of repair. Texas Heart Inst. J., 16: 72-75, 1989 .
3 COOLEY, D. A. - Ventricular endoaneurysmorrhaphy: a simplified repair for extensive postinfarction aneurysm. J. Cardiac. Surg., 4: 201-205, 1989.

4 COOLEY, D. A.; COLLINS, H. A.; MORRIS Jr., G. C.; CHAPMAN, D. W. - Ventricular aneurysms after myocardial infarction: surgical excision with use of temporary cardiopulmonary bypass. JAMA, 167: 557-560, 1958.

5 DOR, V.; SAAB, M.; COSTE, P.; KORNASZEWSKA, M.; MONTIGLIO, F. - Left ventricular aneurysm: a new surgical approach. Thorac. Cardiovasc. Surg., 37 11-19, 1989. 
BRAILE, D. M.; MUSTAFÁ, R. M.; SANTOS, J. L. V.; ARDITO, R. V.; ZAIANTCHICK, M.; COELHO, W. M.; GARZON, S. A. Correção da geometria do ventrículo esquerdo com prótese semi-rígida de pericárdio bovino. Rev. Bras. Cir. Cardiovasc., 6(2): 109-115, 1991.

6 DOR, V.; SABETIER, M.; ROSSI, P.; MAIOLI, M. - Inuited letter concerning: simulated left ventricular aneurysm and aneurysm repair in swine. J. Thorac. Cardiovasc. Surg., 100: 793-794, 1990.

7 JATENE, A. D. - Left ventricular aneurysmectomy: resec- tion or reconstruction. J. Thorac. Cardiovasc. Surg., 89: 321-331, 1985.

8 NICOLOSI, A. C.; WENG, Z. C.; DETWILER, P. W.; SPOTNITZ, H. M. - Simulated left ventricular aneurysm and aneurysm repair in swine. J. Thorac. Cardiovasc. Surg., 100: 745-755, 1990. 